\title{
Risk, Uncertainty, and Learning in Nanomaterials Regulation: An Analytical Framework
}

\begin{abstract}
Aline Reichow*
The regulation of nanomaterials is still surrounded by scientific uncertainty regarding their potential human health risks. It is therefore useful to consider learning approaches in the process of regulation. Effective regulation is conceptualised with regard to collaborative activities of state and non-state actors that enable mutual learning regarding the health risks of nanomaterials. A theoretical framework is offered for studying learning processes in the area of occupational safety and health. Drawing on the network governance literature, three learning types (namely substantive, strategic, and institutional learning) are distinguished. Analytical conditions are proposed and applied to the case of nanomaterials in Germany, thereby offering insights into learning processes in industry-initiated collaborative activities. It is concluded that the development of trust among network collaborators is decisive for learning processes. Accordingly, a proposal for research into specific stages of trust development is made.
\end{abstract}

\section{Introduction}

Since approximately 2004, a general concern has been voiced regarding the potential health risks of nanomaterials starting a debate and research aimed at uncovering and managing the risks of nanomaterials. ${ }^{1}$ Such a development can be seen as a common effort to protect society from the potential detrimental effects of technological innovations while leveraging the economic potential of these technologies. What would appear special in the case of nanomaterials is that, from the onset, a wide array of public and private actors in Europe, and particularly in Germany, began to collaborate to ensure the responsible development of nanomaterials. ${ }^{2}$ This joint effort appears to be the result of learning from past experiences with the introduction of genetically modified organisms (GMOs) in Germany, and in the European Union (EU) more generally, from 1990 onwards. ${ }^{3}$ In that case civil society groups were only, it would at least publically seem, brought into discussions with the government at a late stage, after a generally negative image of GMOs had already been 'anchored' in public opinion, with a focus on their potential risks to health and the environment. As a result, it was no longer possible to discuss the proposed positive ef- fects of this new technology resulting in the rejection of GMOs in the EU at large.

Learning from these experiences, research was carried out into the potential human health risks of nanomaterials at an early stage, i.e. in parallel to the development of this technological field. ${ }^{4}$ More than a decade of research has indicated that nano-sized materials do not seem to possess any 'nanospecific' toxicity, i.e. completely novel mechanisms of toxicity as result of their size. ${ }^{5}$ In other words, no sudden

* Federal Institute for Occupational Safety and Health (BAuA) Dortmund, Germany.

1 Aline Reichow and Diana M. Bowman, "Roles of Non-Governmental Organizations in the Governance of Nanomaterials", in Diana M. Bowman et al. (eds), Practices of Innovation and Responsibility: Insights from Methods, Governance and Action (Berlin: AKA, 2015) pp. 69-83.

2 Aline Reichow, Effective Regulation under Conditions of Scientific Uncertainty. How Collaborative Networks Contribute to Occupational Health and Safety Regulation for Nanomaterials (PhD thesis on file at the University of Enschede, 2015).

3 Reichow and Bowman, Roles of Non-Governmental Organizations, supra, note 1

4 Thomas Gebel and Roland Landsiel, "Inhalte der Sicherheitsforschung: Langzeitwirkungen biobeständiger Nanostäube", 10 Gefahrstoffe Reinhaltung der Luft (2013), pp. 414-427.

5 Ken Donaldson and Craig A. Poland, "Nanotoxicity: challenging the myth of nano-specific toxicity", 24(4) Current Opinion in Biotechnology (2013), pp. 724-734. 
change in hazard was observed for particles below 100 nanometres $(\mathrm{nm})$ in one dimension. ${ }^{6}$ Therefore, to consider all nanomaterials as a priori hazardous seems unjustified. However, data on the chronic adverse effects of nanomaterials are sparse. ${ }^{7}$ In order to facilitate hazard assessment, and thereby risk assessment, ${ }^{8}$ it has been proposed that nanomaterials be categorised into three groups according to their route of exposure and mode of action:

1. Chemically mediated toxicity (release of toxic components, functional groups resulting in toxicity depending on chemical identity),

2. Fibre toxicity (respirable, biopersistent, rigid, World Health Organization (WHO) fibre dimen$\operatorname{sion}^{9}$, no chemically mediated toxicity leading to asbestos-like action (inflammation, lung and mesothelial tumours),

3. Granular particle toxicity (respirable, biopersistent, no chemically mediated toxicity leading to inflammation and tumours). ${ }^{10}$

Such efforts to facilitate hazard assessment for nanomaterials are important as it is likely that rigid materials in the World Health Organization (WHO) fibre dimension, such as some long and thin multiwalled carbon nanotubes (MWCNTs) handled at workplaces, put employees at risk as they present a hazard comparable with that of asbestos. The International Agency for Research on Cancer (IARC), which forms part of the WHO, has assessed one spe-

6 Thomas Gebel et al., "Manufactured nanomaterials: categorization and approaches to hazard assessment", 88 Archives of Toxicology (2014), pp. 2191-2211.

7 Ibid.

8 Hazard and exposure data are required in order to conduct a risk assessment.

9 Fibrous particles with a specific geometry and a high aspect ratio (so-called WHO fibres with length $>5 \mu \mathrm{m}$, diameter $<3 \mu \mathrm{m}$, aspect ratio $>3: 1$ ).

10 Gebel et al., Manufactured nanomaterials, supra, note 6.

11 Yann Grosse et al., "Carcinogenicity of fluoro-edenite, silicon carbide fibres and whiskers, and carbon nanotubes", 15(13) The Lancet Oncology (2014), pp. 1427-1428.

$12 \mathrm{NIOSH}$, "Nanotechnology", 2015, available on the internet at: $<$ http://www.cdc.gov/niosh/topics/nanotech/> (last accessed on 09 October 2015).

13 Kai Savolainen, Ulrika Backman, Derk Brouwer, Bengt Fadeel, Teresa Fernandes, Thomas Kuhlbusch, RobertLandsiedel, Iseult Lynch and Lea Pylkkänen, "Nanosafety in Europe 2015-2025: Towards Safe and Sustainable Nanomaterials and Nanotechnology Innovations", 2013, available on the internet at: <http://www .ttl.fi/en/publications/Electronic publications/Nanosafety in _europe_2015-2025/Documents/nanosafety_2015-2025.pdf> (last accessed on 27 June 2013). cific type of MWCNTs as potentially carcinogenic; for other types, insufficient data was available to assess their carcinogenic potential. ${ }^{11}$ Moreover, "traditional" testing strategies offer only a limited view; they must be adapted and validated in parallel to the material innovation process. ${ }^{12}$

It is important to acknowledge these challenges because employers in Europe are by default legally obliged to protect the health of their employees who handle chemical substances, including nanomaterials, in workplaces by having risk assessment and management in place. This employer obligation is grounded in various EU directives and in the Registration, Evaluation, Authorisation and Restriction of Chemicals (REACH) Regulation and it has to be implemented by the Member States. However, scientifically coherent risk data on particular nanomaterials is still scarce, which makes it difficult to conduct risk assessment for such nanomaterials. Therefore, in order to be able to comply with existing regulations, employers need to learn how to make risk assessment applicable to nanomaterials. Accordingly, regulators need to learn whether existing health and safety frameworks are evidently protecting employee health. $^{13}$

This article argues that regulators and employers, who collaborate in common activities, can mutually learn from each other how to improve existing risk assessment frameworks for nanomaterials. The crucial question in this context is how we can research such learning processes. The question is answered by developing a tentative analytical framework for learning processes in relation to technological regulation characterised by scientific uncertainty. So far no comparable analytical frameworks are available. To demonstrate how the framework can help to research learning processes, it is applied to the case of nanomaterials in Germany.

Learning processes are investigated in collaborative activities that include representatives of German industry, regulatory agencies, academia, consultancies and non-governmental agencies. In total seven collaborative activities are investigated, ranging from internal working group meetings to public workshops and surveys. The activities took place in the time period between 2003 and 2014 and were initiated by the German Chemical Industry Association (VCI) with the goal to make risk assessment applicable to nanomaterials. The investigation of learning processes is based on data from publicly avail- 
able (policy) documents related to the collaborative activities and qualitative, semi-structured interviews with involved actors. The data was generated in the context of a $\mathrm{PhD}$ project. The interviews were done between 2012 and 2014 either in person or by phone. In total 23 interviews were conducted, which lasted on average 45 minutes. The interviews were coded and analysed following the analytical categories developed in section four of this article. ${ }^{14}$

Following the introduction, in section two the current European and German regulatory framework is spelled out under which nanomaterials in the occupational safety and health (OSH) environment are captured and challenges in regard to effective regulation are identified. In section three, key challenges are conceptualised as a network governance problem to be dealt with through collaborative activities by non-state and state actors that facilitate learning. On this basis, in section four, analytical categories and conditions for the study of collaborative activities are developed and applied to the case of nanomaterials EU OSH regulation as implemented in Germany. This section forms the main body of the article. In section five, key findings are discussed and aspects for future research in the field of regulation and governance are proposed.

\section{Regulatory Framework and Challenges of Effective Regulation}

Under the current regulatory framework in the EU, nanomaterials handled in workplaces are not regulated specifically but generally as 'chemical substances'. By default, employers are legally obliged to protect the health of their employees who handle chemical substances in workplaces, ideally through having risk assessment and management in place. In Europe, one of the key pieces of legislation with regard to health and safety at work is the Framework Directive 89/391/EEC of 12 June 1989 on the introduction of measures to encourage improvements in the safety and health of workers at work. It lays down the specific tasks entailed in the employer's duty to ensure the safety and health of workers; to that end, the employer shall be in possession of an assessment of the risks to safety and health at work, and accordingly shall decide on the protective measures to be taken and the protective equipment to be used. ${ }^{15}$ In addition, Directive 98/24/EC lays down minimum re- quirements for worker protection from risks to their safety and health that (are likely to) arise from the effects of chemical agents handled at the workplace. Employers shall determine whether any hazardous chemical agents are present at the workplace. If so, any risk to the safety and health of workers arising from those chemical agents shall be assessed. ${ }^{16}$

In addition to OSH legislation, chemicals in workplaces are also regulated by the Registration, Evaluation, Authorisation and Restriction of Chemicals (REACH) Regulation. Pursuant to Article 6(1) of the REACH Regulation, importers and manufactures must register a chemical substance each calendar year. The registration is volume-based and must consist of a technical dossier and a safety report containing information about the substance's properties, together with a safety assessment that includes a hazard characterisation and, under certain circumstances, an exposure assessment and a risk characterisation. ${ }^{17}$ Accordingly, a registrant shall identify and apply appropriate risk management measures. ${ }^{18}$

Employers in the EU are thus legally obliged to care for the safety and health of their employees by having risk assessment for chemicals in place. In case of non-compliance employers may be subject to civil penalty imposed by a court. The EU Member States are responsible for the implementation of EU OSH and chemicals regulation as well as for the transposition of directives into national law. As this article investigates learning processes in the case of nanomaterials in Germany, the implementation of directives into German legislation are explained briefly.

Framework Directive 89/391/EEC is implemented into German legislation through the Safety and Health at Work Act, or the 'Arbeitsschutzgesetz' (ArbSchG). Employers must ensure, and improve, health and safety at the workplace by conducting risk as-

14 Detailed information regarding the selection of interviewees, the analysis of the empirical data, and the collaborative activities analysed is available online; see Reichow, Effective Regulation, supra, note 2 .

15 Framework Directive 89/391/EEC on the introduction of measures to encourage improvements in the safety and health of workers at work, section II, article 9(1), OJ 1989 L 183/1.

16 Council Directive 98/24/EC on the protection of the health and safety of workers from the risks related tochemical agents at work, OJ 1998 L 131/11.

17 Commission Regulation (EC) No 1907/2006 of the European Parliament and of the Council on the Registration, Evaluation, Authorisation and Restriction of Chemicals (REACH), articles 6 and 14, OJ 2006 L 136/3.

18 Ibid. 
sessments for (among others) chemicals that may involve a risk and that are handled at the workplace. The results of the risk assessment serve to inform the choice of health and safety measures. The employer must document the results of the risk assessment and the measures that have been taken to ensure the health and safety of workers.

In addition to the ArbSchG, the Hazardous Substances Ordinance of 26 November 2010 (BGBl. I p. 1643) ('Gefahrstoffverordnung', GefStoffV) is relevant for OSH and serves to implement Council Directive 98/24/EC. As such, employers are required-based on the results of the risk assessment-to establish whether workers perform activities involving hazardous substances, or whether hazardous substances may arise or be released during workplace activities. If this is the case, all risks to the health and safety of workers must be assessed. In addition, the risk assessment and measures aimed at ensuring, or improving, health and safety at the workplace shall be in accordance with various Technical Rules for Hazardous Substances ('Technische Regeln für Gefahrstoffe', TRGS), if available, from the Federal Institute for Occupational Safety and Health (BAuA). TRGS are determined and adapted by the Hazardous Substances Committee ('Ausschuss für Gefahrstoffe', AGS) of the Federal Ministry of Labour and Social Affairs and reflect the state of the art of technology, science, and occupational health related to work with hazardous substances.

Against this backdrop, employers are likely to face difficulties in complying with the obligation to have risk assessment for nanomaterials in place. As mentioned earlier, this is due to the continuing scarcity of scientifically coherent toxicity and exposure risk

19 Kai Savolainen et al., "Nanosafety", supra, note 13.

20 Bärbel R. Dorbeck-Jung, "How can hybrid nanomedical products regulation cope with wicked governability problems", in Morag Goodwin, Bert-Jaap Koops and Ronald Leenes (eds), Dimensions of Technology Regulation (Nijmegen: Wolf Publishers, 2010), pp. 63-84.

21 Graeme A. Hodge, Diana M. Bowman and Andrew D. Maynard (eds), International Handbook on Regulating Nanotechnologies (Massachusetts, US: Edward Elgar Publishing, 2010).

22 Carolyn Abbot, "Bridging the Gap - Non-state Actors and the Challenges of Regulating New Technology", 39(3) Journal of Law and Society (2012), pp. 329-358.

23 Cary Coglianese, "Business Interest and Information in Environmental Rulemaking", in Michael E. Kraft and Sheldon Kamienieki (eds), Business and Environmental Policy (Cambridge, MA: MIT Press, 2007), pp. 185-210.

24 Hans Opschoor and Kerry Turner, Economic Incentives and Environmental Policies: Principles and Practice (Dordrecht: Kluwer Academic Publishers, 1994). data for particular nanomaterials, which makes it difficult to apply risk assessment to these nanomaterials. Furthermore, it is challenging for regulators to know whether existing health and safety frameworks are evidently protecting employees' health. ${ }^{19}$

Given the scientific uncertainty, regulatory scholars have signified the regulation of nanotechnology as a "wicked" public policy problem. ${ }^{20}{ }^{21}$ Fundamental data relating to certain nanomaterials need to be obtained from industry so as to allow regulators to learn to assess and deal with potential risks adequately.

Nanomaterials, as is generally the case with emerging technologies, bring with them an asymmetry in the possession of resources such as knowledge or scientific expertise critical to risk governance. Non-state actors, such as manufacturers, typically have more resources than government agencies. ${ }^{22}{ }^{23}$ It is unclear how sharing of required resources in collaborative activities can contribute to the process of regulation. To shed light on this issue, in this article collaboration between regulators and industry is conceptualised by employing the literature on governance networks. Against this background, a framework is developed for the analysis of learning in governance networks that allows us to understand how such networks can contribute to the effective regulation of nanomaterials through learning processes.

Most often effective regulation is defined as the degree to which policy goals have been achieved through the rule compliant behaviour of the regulated parties. ${ }^{24}$ In the case of nanomaterials OSH regulation, the prevailing scientific uncertainty means that we do not know whether existing rules evidently mitigate risks and protect employees or whether companies are able to comply with these rules. Therefore, when talking about effective regulation we need to consider practices by which rule compliance is prepared; namely through activities by which regulatees understand and learn how to "translate" general OSH rules into the specific context of nanomaterials so as to become rule-compliant. For example, sectoral business associations or research institutions can organise workshops where knowledge is exchanged and generated and, on this basis, guidance material can be developed that facilitates rule compliance under specific circumstances.

As such, we consider effective nanomaterials OSH regulation to be focused on the processes of compliance, namely activities that prepare compliance with 
the employer legal obligation to carry out risk assessment for chemicals handled by employees. While regulatees, i.e. industry, are likely to participate in these processes (in order to achieve compliance), regulators may also participate as they can use newly generated knowledge to ensure that science-based OSH rules are in place.

\section{Network Governance}

The network governance literature provides useful approaches for the analysis of learning in collaborative activities in the context of nanomaterials because it describes processes of collaboration aimed at solving complex policy problems having at least two dimensions of uncertainty: Firstly, due to insufficient knowledge the problem, including potential solutions, cannot be defined clearly leading to substantial uncertainty. Secondly, uncertainty stems from the presence of many actors, each pursuing their own goals and strategies for how to deal with the problem. ${ }^{25}$ In other words, actor behaviour takes place in complex "games" of collaboration. ${ }^{26}$

In the case of nanomaterials, for example, there is insufficient knowledge on validated methodological requirements in toxicity testing and in exposure monitoring under real-life conditions. Accordingly, there is a need to extend the existing knowledge base. In addition, many private and public actors - chemical business associations, companies, regulatory agencies, (federal) research institutes, academia, consultancies, labour unions, non-governmental organisations, social accident insurers - are actively engaged in the $\mathrm{OSH}$ debate regarding nanomaterials. ${ }^{27}$ The diversity of actor groups leads to complex and uncertain strategic games.

In order to decrease substantial uncertainty it is necessary to deploy key resources from the collaborators (e.g. skills, knowledge, decision-making authority). Key resources are exchanged and negotiated according to general and individual actor strategies. As such, collaboration is organised around relations of resource dependency. ${ }^{28}$ Collaboration is successful, i.e. creates scientific consensus, when resource exchange enables the development of mutual perceptions and agreements based on which common action and joint solutions are realised. ${ }^{29}$

The problem of effective nanomaterials OSH regulation can be characterised as a network governance problem: many actors from industry, regulatory agencies and others show an interest in cooperating with the goal of protecting the safety and health of employees who handle nanomaterials. ${ }^{30}$ Crucial resources include scientific data/knowledge on nanomaterials handled in workplaces and decision-making authority in the area of OSH. The collaborators depend upon one another in the sense that regulators require sound scientific data to ensure sciencebased rules, while industry depends on regulators because only they have the authority to set (new and possibly stricter) regulation and legislation that businesses need to comply with.

Analysing collaborative network activities requires acknowledging that networks are not static entities; rather, they are dynamic in character with collaboration and negotiation being an ongoing process. In order to deal with this element of dynamism, the network governance literature conceptualises the process of collaboration in "rounds" of interaction and negotiation between actors. Problems and solutions are relevant to processes of negotiation if actors perceive and articulate them as such. ${ }^{31}$ When actors mutually adjust their positions during processes of deliberation, negotiation paves the way for decision-making directed at making progress towards solving a certain problem. Decisionmaking may be studied on three levels of analysis: the actor, the game, and the network. ${ }^{32}$

To conduct an actor analysis means formulating a concrete problem identity based on the identification of key actors in a network, their positions as to the problem definition and potential solutions, and

25 Johannes F.M. Koppenjan and Erik-Hans Klijn, Managing Uncertainties in Networks. A network approach to problem solving and decision making (London: Routledge, 2004).

26 Fritz W. Scharpf, Games real actors play; actor-centered institutionalism in policy research (Boulder, US: Westview Press, 1997).

27 Reichow, Effective Regulation, supra, note 2.

28 Fritz W. Scharpf, "Interorganizational policy studies: issues, concepts and perspectives", in Kenneth Hanf and Fritz W. Scharpf (eds), Interorganizational Policy Making; Limits to Coordination and Central Control (London: Sage, 1978).

29 Koppenjan and Klijn, Managing Uncertainties, supra, note 24.

30 Aline Reichow and Bärbel Dorbeck-Jung, "Discovering specific conditions for compliance with soft regulation related to work with nanomaterials", 7(1) NanoEthics (2013), pp. 83-92.

31 Geert R. Teisman, Complex decision-making, a pluricentric view $3^{\text {rd }}$ ed. (The Hague: Vuga, 1998).

32 Koppenjan and Klijn, Managing Uncertainties, supra, note 24. 
their resource dependencies in relation to the problem situation. ${ }^{33}$ Dependence among actors is influenced by their willingness, or interest, to share resources in the network to help dealing with the problem of content uncertainty in relation to the problem. ${ }^{34}$

The second, or game, level of analysis considers the process of interaction between the collaborators. It enables to understand potential stagnation in the course of negotiation processes that may prevent collective action in view to reaching decisions. ${ }^{35}$ It may occur that actors realign their strategies and goals during the process of negotiation as a consequence of stagnation or blockades. ${ }^{36}$ Stagnation and blockades may have a substantive (knowledge) and a social component. Understanding the cause(s) of asymmetry between actors facilitates the development of strategies for overcoming stalemate and for continuing collaboration.

In the network level of analysis, the rules of behaviour that structure interaction and decision-making actors are identified and investigated by considering the institutional context. ${ }^{37}$ Formal (legal) and informal rules of behaviour that frame interaction processes are examined and how these rules might change over time. On this basis, new rules may be developed to structure and coordinate specific behaviour in the network.

\section{Analytical Categories and Application to the Case of Nanomaterials in Germany}

Based on the foregoing section, we can now distil specific analytical categories that provide us with con-

\footnotetext{
33 Ibid.

34 Ibid.

35 Ibid.

36 Elinor Ostrom, Governing the Commons. The Evolution of Institutions for Collective Action (Cambridge: Cambridge University Press, 1990)

37 Koppenjan and Klijn, Managing Uncertainties, supra, note 24.

38 Instead of using the original term "cognitive learning" used by Koppenjan and Klijn, we use the term "substantive learning" for reasons of clarity.

39 Koppenjan and Klijn, Managing Uncertainties, supra, note 24.

40 For detailed information on the collaborative activities of the $\mathrm{VCl}$ network, see Reichow, Effective Regulation, supra, note 2. All case-related data in this article is based on Reichow.
}

ditions for the study of learning processes in networks. The underlying argument is that actors who share specific resources during processes of collaboration can mutually learn from each other how to deal with the wicked problem, i.e. how to improve existing risk assessment frameworks for nanomaterials.

Learning refers to a sustainable increase in shared knowledge and methods between the collaborators. Learning is the overarching category for the analysis of collaborative activities and is broken down into three specific analytical categories. These take the form of three types of learning in the areas of content (substantive learning ${ }^{38}$ ), process (strategic learning), and network (institutional learning). ${ }^{39}$

While this proposed differentiation is useful it needs to be acknowledged that the three learning types are not yet sufficiently operationalised by Koppenjan and Klijn in order to allow for empirical investigations. Therefore, the author's general ideas are used as a starting point for finding conditions under which learning can emerge. By drawing selectively on additional theoretical and (where available) empirical studies on networks and the learning types conditions are proposed under which learning in view to the problem of nanomaterials risk assessment can emerge (see Table 1). The conditions are applied to the case of nanomaterials OSH in Germany. Here, an analysis is made of activities directed at contributing to effective nanomaterials OSH regulation in the case of one collaborative network, initiated by a chemical business association. Specifically, the analysis focuses on collaborative activities of the German Chemical Industry Association (VCI) between 2003 and 2014. In total seven activities that are supported by publicly available (policy) documents are investigated. ${ }^{40}$

\section{Substantive Learning}

\section{a. Theoretical Framework}

Substantive learning refers to gaining increased knowledge and insight about the nature, cause and effects of the problem of nanomaterials risk assessment, potential solutions, and their consequences. During this process multiple scientific insights and actor interests are deliberated and negotiated resulting in common agreements. Two forms of substan- 
Table 1: Analytical categories and conditions for the evaluation of effective nanomaterials OSH regulation.

\begin{tabular}{|l|l|l|}
\hline LEVEL & ANALYTICAL CATEGORY & CONDITIONS \\
\hline Actor level & $\begin{array}{l}\text { Substantive learning } \\
\text { Characteristic: } \\
\text { Scientific expertise }\end{array}$ & $\begin{array}{l}\text { 1. Relevant actors collaborate } \\
\text { 2. Exchange of knowledge and (risk) data } \\
\text { 3. Increased understanding of how to deal with core problems relat- } \\
\text { ed to nanomaterials risk assessment } \\
\text { 4. Generation of novel scientific facts }\end{array}$ \\
\hline Game level & $\begin{array}{l}\text { Strategic learning } \\
\text { Characteristic: Trust }\end{array}$ & $\begin{array}{l}\text { 1. Meetings over a longer period of time } \\
\text { 2. Intensified actor relations } \\
\text { 3. Reliance among collaborators } \\
\text { 4. Realisation of common goals } \\
\text { 5. Disagreement among collaborators is addressed } \\
\text { and solved } \\
\text { 6. Development of additional collaborative activities }\end{array}$ \\
\hline Network level & $\begin{array}{l}\text { Institutional learning } \\
\text { Characteristic: Rules }\end{array}$ & $\begin{array}{l}\text { 1. Development of informal agreements } \\
\text { 2. Design of soft rules of behaviour } \\
\text { 3. Soft rules become hardened }\end{array}$ \\
\hline
\end{tabular}

tive learning can be distinguished: joint image building and goal intertwinement. ${ }^{41}$ The former is accomplished when interaction and scientific research between e.g. companies, business associations and policy-makers allows the actors to agree both on a specific problem related to nanomaterials risk assessment and on the potential consequences of proposed solutions. When research has been conducted but the key actors do not agree on its meaning and significance, superfluous knowledge emerges: knowledge is generated but does not move forward the problemsolving process and therefore increases uncertainty. ${ }^{42}$ Joint image building requires deliberation and negotiated knowledge, namely the agreement about insights based on research findings that are scientifically defensible. The solution that is agreed upon enables considerable improvement of an existing situation for most actors.

On this basis, the key characteristic of substantive learning is scientific expertise to be studied by means of four conditions that are assumed to build on each other in the described sequence. When more than half of the conditions for a learning type are met we can speak of "strong" learning. When less than half of the conditions are met "limited" learning emerges. Hence, not all of the conditions need to be met in order for learning to emerge.

Substantive learning in regard to making risk assessment applicable for nanomaterials is, first, as- sumed to be possible only when "relevant actors collaborate". Relevant actors are those who bring resources into the collaboration that are essential for solving the problem at hand and cannot easily be substituted. ${ }^{43}$ Here, actors are relevant when they hold the crucial resource scientific (risk) data and knowledge relating to nanomaterials, which is necessary for solving the problem of nanomaterial risk assessment. Furthermore, when actors hold the resource decision-making authority they are considered relevant because they can decide which solutions regarding the problem of nanomaterials OSH are to be implemented into rulemaking.

Second, when these actors "exchange their knowledge and (risk) data" with other network collaborators a basis for meaningful deliberation and negotiation of scientific insights in view to conducting risk assessment for nanomaterials can be established.

Third, when such deliberations and discussions lead to an "increased understanding of how to deal with core problems related to nanomaterials risk assessment", another step towards substantial learning is realised.

\footnotetext{
41 Koppenjan and Klijn, Managing Uncertainties, supra, note 24.

42 Odette van de Riet, Policy Analysis in Multi-actor Policy Settings (Delft: Eburon, 2003).

43 Scharpf, Interorganizational policy, supra, note 27.
} 
Finally, with the "generation of novel scientific facts" to help make (aspects of) traditional risk assessment applicable for nanomaterials, substantial learning is achieved. The actors have a fundamentally better understanding of core problems as compared to the situation prior to collaboration. New scientific facts can relate, for instance, to knowledge on the risk characterisation of certain nanomaterials. Next, the analytical conditions are applied to the case of nanomaterials in Germany to investigate learning processes in the collaborative activities initiated by the VCI.

\section{b. Application to the Case of Nanomaterials}

In the VCI-initiated collaborative activities between 2003 and 2014, all four analytical conditions of substantive learning were met leading to "strong" learning. With regard to the first condition, relevant actors have collaborated, i.e. those actors who held the resources knowledge or decision-making authority related to nanomaterials OSH. These included staff and member companies of the VCI and another association, representatives of two regulatory agencies (the Federal Ministry of Labour and Social Affairs (BMAS), and the Federal Ministry of Education and Research (BMBF)), two federal research institutes (the Federal Institute for Occupational Safety and Health (BAuA) and the Federal Institute for Risk Assessment (BfR)), and various scientists from academia. In workshops, topically oriented meetings, conferences, and internal working group meetings, the collaborators exchanged risk-relevant knowledge. The exchanged knowledge took the form of aggregate data (i.e. cumulative information), general experiences, and published state-of-the-art data. Knowledge was also exchanged in the form of raw data. Through this knowledge exchange, the collaborators gained an increased understanding of specific aspects related to (human) toxicological aspects of (specific) nanomaterials, exposure measurement technology/control, and the characterisation of risks associated with nanomaterials generally. On this basis,

\footnotetext{
44 Koppenjan and Klijn, Managing Uncertainties, supra, note 24.

45 Ibid.

46 Roy J. Lewicki, Edward C. Tomlinson and Nicole Gillespie, "Models of Interpersonal Trust Development: Theoretical Approaches, Empirical Evidence, and Future Directions", 32(6) Journal of Management (2006), p. 992.
}

many new scientific facts that were relevant for making various aspects of risk assessment applicable to eleven types of nanomaterials were generated and published in peer-reviewed scientific journals. Based on these findings, the research project NanoCare (2005) was tailored and funded by the BMBF.

\section{Strategic Learning}

\section{a. Theoretical Framework}

Strategic learning refers to the quality of interaction in the process of collaboration and is evaluated by the key characteristic trust. We speak of strategic learning when network actors develop a growing capacity to collaborate despite pursuing different individual goals. ${ }^{44}$ When actors with individually different backgrounds and beliefs work together towards the common goal of ensuring health and safety at workplaces where nanomaterials are handled, different points of view come together how to reach this goal. Naturally, interaction in networks implies that individual actor goals and strategies diverge from each other and from the overall network goal, which may lead to disagreement and conflict. When such conflict is not addressed and solved, goal divergence can lead to blockades and stagnation in collaboration. But when disagreement between actors is addressed openly and solved to the overall satisfaction of collaborators, actors learn that others in the network can be trusted to act in view to the common network goal, even though they may have different individual opinions on specific issues ${ }^{45}$. Under these circumstances actors are willing to accept certain risks, in terms of personal loss, because they trust that other actors will refrain from opportunistic behaviour where there is an opportunity for such behaviour.

The literature on trust is still fragmented and does not provide clear answers how trust among network collaborators develops and progresses over time. Lewicki et al. (2006) state that "most of the empirical trust research is characterised by static, 'snapshot' studies that measure trust at a single point in time (...) they provide limited insight into the dynamic nature of the growth and decline of trust over time within interpersonal relationships". ${ }^{46}$ In line with the authors' call for research on the dynamic nature of trust, in this article trust is conceived of in different forms, 
which emerge and develop over time. ${ }^{47}$ As such, trust is rated along various indicators of different stages: trust begins at a calculative stage, initiated by reputation or structures that reward trustworthiness. Trust grows with increased knowledge of others and when collaborators develop shared values or emotional bonds. Trust declines when positive expectations of others are disappointed. Although we will briefly touch upon the relationship between trust and distrust, due to limited space in this article the main focus is on understanding how trust, rather than distrust, develops over time. Hence, for in-depth discussions of distrust other authors need to be consulted. ${ }^{48}$

The literature points to three basic characteristics of trust: risk, expectation and vulnerability. Trust refers to vulnerability because actors who trust each other put themselves willingly into a vulnerable position. They expect that other actors will refrain from opportunistic behaviour even though the opportunity for it may emerge. ${ }^{49}$ As they do not have a guarantee that such opportunistic behaviour will not arise, they take a certain risk that other actors do not behave as expected ${ }^{50}$ while having the fundamental belief that actors take each other's interests into account in the process of collaboration. ${ }^{51}$ In other words, actors trust that other actors (the trustees) will respect their interests as "trustor". ${ }^{52}$

Trust relates to feelings or perceptions as well as to a rational evaluation or reasoning why and when other people might (not) be trustworthy. Trustworthiness is defined as the ability and willingness to take into account not only material self-interest but

47 E.g. Roy J. Lewicki and Barbara B. Bunker, "Developing and maintaining trust in work relationships", in Roderick M. Kramer and Tom R. Tyler (eds), Trust in organizations: Frontiers of theory and research (Thousand Oaks: Sage, 1996), pp. 114-139; Debra L. Shapiro, Blair H. Sheppard and Lisa Cheraskin, "Business on a handshake", 8(4) Negotiation Journal (1996), pp. 365-377.

48 E.g. Roderick M. Kramer, "The sinister attribution error: Paranoid cognition and collective distrust in organizations", 18(2) Motivation and Emotion (1994), pp. 199-230.

49 Mari Sako, "Does trust improve business performance?", in Christel Lane and Reinhard Bachmann (eds), Trust within and between organizations: Conceptual issues and empirical applications (Oxford, UK: Oxford University Press, 1998), pp. 88-117.

50 Simon Deakin and Frank Wilkinson, "Contract law and the economics of interorganizational trust", in Christel Lane and Reinhard Bachmann (eds), Trust within and between organizations: Conceptual issues and empirical applications (Oxford, UK: Oxford University Press, 1998), pp. 146-172.

51 Bart Nooteboom, Trust: Forms, Foundations, Functions, Failures and Figures (Cheltenham: Edward Elgar, 2002).

52 Bart Nooteboom, Management van Partnerships (Schoonhoven: Academic Service, 2000). also more altruistic motives like loyalty, justice or legitimate conduct. ${ }^{53}$

To analyse strategic learning in collaborative networks, six conditions are derived from the trust literature. These conditions are assumed to, partly, build upon each other in the following order: First, building and maintaining trust among collaborators requires "meetings over a longer period of time". Various studies support the idea that trust develops slowly over time because collaborators need to become familiar with each other through personal interaction and experiences. ${ }^{54} 55$ The literature does not specify what "meetings over a longer period of time" practically means but mentions that they are not "one-time-only affairs" ${ }^{56}$ Little is known about how much time is necessary for trust to develop and how trust develops over time. ${ }^{57}$

Second, based on meetings over a longer period of time, "intensified actor relations" are a pre-condition for trust to develop. Actor relations become intensified when collaborators get to know each other better and become familiar with one another. Based on (past) experiences in processes of interaction, trust can develop. ${ }^{58}$ Thus, having more information about collaborators available from personal interaction is important for trust to be build. In addition, such information may be derived from impersonal or second-hand information on collaborators, e.g. their reputation based on recommendations or a "good name" in professional journals. ${ }^{59}$

Third, after actors have intensified their relationships, "reliance among collaborators" may develop.

53 Bart Nooteboom, Trust and innovation (Tilburg: Tilburg University, 2010).

54 Jurian Edelbos and Erik-Hans Klijn, "Trust in complex decisionmaking networks. A theoretical and empirical exploration", 39(1) Administration \& Society (2007), pp. 25-50.

55 Scott B. Droege, Jonathan R. Anderson and Matthew Bowler, "Trust and organizational information flow", 9(1) Journal of Business and Management 9(1), pp. 45-59.

56 Robert Axelrod, The evolution of cooperation (New York: Basic Books, 1984).

57 D. Harrison McKnight and Norman L. Chervany, "Reflections on an initial trust-building model", in Reinhard Bachmann Akbar Zaheer (eds), Handbook of Trust Research (Cheltenham, UK: Edward Elgar, 2006), pp. 29-51.

58 Ranjay Gulati, "Does Familiarity Breed Trust? The Implications of Repeated Ties for Contractual Choice in Alliances", 38(1) Academy of Management Journal (1995), pp. 85-112.

59 John J. Gabarro, "The development of trust. Influence and expectations", in Anthony G. Athos and John J. Gabarro (eds), Interpersonal behavior: communication and understanding in relationships (Englewood Cliffs, NJ: Prentice-Hall, 1978), pp. 290-303. 
Reliance is a sign that trust has begun to emerge. Reliance refers to two elements: predictability and control of others' behaviour in a network. In regard to the former aspect, reliance refers to consistency of other actors' behaviour. ${ }^{60}$ Hence, actors know each other well based on personal experiences and believe that others will adhere to agreements that have been made formally or informally. ${ }^{61}$ But this belief is adaptive: when trust among collaborators is betrayed, behaviour becomes less predictable and actors realign relationships towards greater levels of control. While trust and control are substitutes, they also are complements ${ }^{62}$ since "complete" trust, e.g. by a government that regulatees will comply with existing rules, is impossible, and where trust ends control is needed. Conversely, "complete" control is impossible and where control ends, trust is needed. Concomitantly, more trust allows for less control. ${ }^{63}$

Fourth, the "realisation of common goals" of the network serves as an indicator that collaborators have developed relationships of trust-rather than as the next step in the development of trust once reliance has emerged among collaborators. When actors can coordinate their activities by giving preference to the achievement of common network goals rather than their own individual goals, trust is present; the collaborators act in this way because they expect that such a situation will not be used against them or will result in opportunistic behaviour by oth-

60 Ibid

61 Erik-Hans Klijn, Jurian Edelbos and Bram Steijn, "Trust in Governance Networks: Its Impacts on Outcomes", 42(2) Administration \& Society (2010), pp. 193-221.

62 Rosalinde Klein Woolthuis, Bas Hillebrand and Bart Nooteboom, "Trust, contract and relationship development", 26(6) Organization Studies (2005), pp. 813-840.

63 Nooteboom, Trust and innovation, supra, note 52.

64 Koppenjan and Klijn, Managing Uncertainties, supra, note 24.

65 Ibid.

66 Ostrom, Governing the Commons, supra, note 35.

67 Edelbos and Klijn, Trust, supra, note 53.

68 Trudy Govier, "Is it a Jungle out there? Trust, distrust, and the construction of social reality", 33 Dialogue (1994), pp. 237-252.

69 Roderick M. Kramer, "Trust and distrust in organizations: emerging perspectives, enduring questions" 50 Annual Review of Psychology (1999), pp. 569-598.

70 Lewicki et al., Models of Interpersonal Trust, supra, note 45

71 Susan Shapiro, "Policing trust", in Clifford D. Shearing and Philip Stenning (eds), Private Policing (Thousand Oaks, CA: Sage, 1987.

72 The concept of capture was originally coined by Stigler (1971).

73 Reichow, Effective Regulation, supra, note 2. er network actors. ${ }^{64}$ On the contrary, when certain network actors try to realise their individual or personal goals at all cost and to the disadvantage of the common network goal(s), blockades and conflicts can emerge that hinder collaboration and may even lead to distrust among collaborators. ${ }^{65}$

Fifth, trust can grow stronger when "disagreement among collaborators is addressed and solved". Any kind of disagreement can affect interaction among collaborators. While disagreement can lead to conflicts and blockades in processes of collaboration, such situations can also mark the beginning of improved cooperation. ${ }^{66}$ For when conflicts are solved to the broad satisfaction of the network actors, for instance through reaching a consensus that is bearable for most actors, collaborators can develop a strong expectation that also future conflict can be handled adequately. ${ }^{67}$ When conflicts among actors cannot be solved but remain an issue that hinders collaboration, discrepancy is nourished, which can feed stalemate in the process of cooperation thereby leading to weakened trust among actors. Weakened trust may be visible in that actors engage less actively in debates than they used to. Weakened trust may also lead to distrust.

Distrust is defined as lack of confidence in the other, a concern that the other may act so as to harm one, that he does not care about one's welfare or intends to act harmfully, or is hostile. ${ }^{68}$ Distrust does not necessarily lead to the termination of collaboration but can also lead actors not to share new resources that are relevant for the network. One component of distrust is suspicion, which describes a situation in which an actor entertains multiple, possibly rival hypotheses about another person's genuineness or goodwill regarding cooperation. ${ }^{69}$ It has been acknowledged that it is probably common within complex relationships to have some combined level of trust and distrust rather than simply - or purely - trust or distrust. ${ }^{70}$ Distrust is not necessarily 'negative' because it can generate appropriate stances towards institutions through vigilance, as a component of resilient organisations in societies. ${ }^{71}$ Distrust may also help to prevent 'capture ${ }^{72}$ of regulators by the interests of industry, who then no longer act in the interest of society. ${ }^{73}$

Capture and corruption are fostered by the very same conditions that foster cooperation, namely through ongoing relationships between businesses and regulators, and through regular repetition of en- 
counters with the same individuals. Capture can be prevented while the advantages of cooperation are secured through continued efforts to engage civil society groups. "Tripartism"74 refers to the empowerment of public interest groups (e.g. non-governmental organisations) through ensuring access to information about regulatory deals. This can even include granting them the ability to punish regulators that fail to punish non-compliant firms and to punish firms themselves. ${ }^{75}$ It can be argued that capture is, to some extent, "natural" because people's affiliations and jobs often change over time, making it difficult to act in the interest of one party alone. It is not uncommon for industry representatives to move into government and for regulators to move from regulatory agencies into industry (the idea of the "revolving door"). Under these conditions, a combined level of trust and distrust can help to deal with the revolving door.

Sixth, with the "development of additional collaborative activities" trust can grow stronger because temporal continuity ensures stability in collaboration. ${ }^{76}$ Likewise, it would appear that the organisation of new partnership activities indicates that past and present relations are based on overall trust. However, new activities can also result in trust relations becoming fragile or even breaking down when actor expectations are not met or trust is damaged by opportunistic behaviour. ${ }^{77}$ Levels of trust and distrust among collaborators may change with continuing encounters and experiences, resulting in complex combined levels of trust and distrust shaped by the specific context in which collaboration takes place. ${ }^{78}$

\section{b. Application to the Case of Nanomaterials}

In the collaborative VCI activities, the majority of the conditions of strategic learning were met, i.e. strong learning emerged. Generally, ample opportunities were provided to meet over a longer period of time and to intensify the relationships among collaborators. Between 2003 and 2014, face-to-face meetings were organised on three to four occasions per year. Most network actors participated in these meetings. Additionally, the collaborators could intensify their relations through the government-initiated NanoDialog, through which approximately three meetings were realised between 2006 and 2011.

The NanoDialog was organised by the Federal Ministry for the Environment, Nature Conservation,
Building and Nuclear Safety (BMUB). It was based on a joint research strategy by various higher federal authorities and aimed at enabling a broad stakeholder debate on the responsible development of nanotechnology. The topic of workplace health and safety, including the (potential) risks of nanomaterials, was covered explicitly. Many actors in the VCI network were represented at the NanoDialogue and thereby had additional opportunities to intensify their relationships.

As a result, the collaborators started to rely on each other. The clearest indicator of this was that the network members shared unpublished data and/or knowledge in the group based on trust beyond control that others would not use such information for their own advantage. Building on this foundation, it was actually possible to realise common network goals without this leading to clashes with particular actors, who would have given preference to realising their own individual goals. This was possible because an independent body balanced the realisation of common network and individual goals. As such, the nonprofit Society for Chemical Engineering and Biotechnology organised and steered meetings and discussions in an impartial manner. No instances of goal divergence or blockades in the collaboration were observed that would have weakened trust relations among network collaborators. As various interviewees pointed out, rather than leading to conflicts, disagreements were welcomed by the participants as a means of inducing lively discussions based on which actors could agree on a compromise or accept disagreement. Various actors initiated additional collaborative activities that emerged within-and were connected to-a broader web of government- and industry-organised collaborative activities related to nanomaterials OSH.

While no apparent instances were apparent where trust among particular actors was weakened through

\footnotetext{
74 Ian Ayres and John Braithwaite, "Tripartism: Regulatory Capture and Empowerment", 16(3) Law \& Social Inquiry (1991), pp. 435-496.

75 Axelrod, The evolution of cooperation, supra, note 55.

76 Lynne G. Zucker, "Production of trust: institutional sources of economic structure, 1840-1920", 8(1) Research in Organisational Behavior (1986), pp. 53-111.

77 Edelbos and Klijn, Trust, supra, note 53

78 Lewicki et al., Models of Interpersonal Trust, supra, note 45.
} 
opportunistic behaviour, this does not imply that no such instances could have existed. Likewise, no instances of "capture" were observed.

\section{Institutional Learning}

\section{a. Theoretical Framework}

The third type of learning, institutional learning, arises when the collaborators develop and communicate agreements and rules of behaviour that support interaction and make behaviour more predictable. ${ }^{79}$ Agreements and rules can be of two types: they can structure, facilitate, and stabilise interaction among relevant actors in a network so that actors know acceptable ways of acting under certain circumstances (process-oriented agreements/rules). Agreements and rules can also refer to practices on how to handle nanomaterials at workplaces most safely based on state-of-the-art science and instrumentation (problem-oriented agreements/rules). ${ }^{80}$ The precursor of full-fledged rules can be informal or ad hoc agreements developed by actors during the process of cooperation. Over time, these agreements can become more durable provisions like soft rules and possibly hard rules that change actor relations in a network (an example of this development is provided in the application of the conditions of institutional learning to the case of nanomaterials).

Most often, soft rules concern rules of behaviour that tell actors what ought to be done under certain circumstances, and do not have legally binding force. ${ }^{81}$ Actors follow soft rules voluntarily, even if only as a result of social pressure to do so. Soft rules

79 Koppenjan and Klijn, Managing Uncertainties, supra, note 24.

80 Koppenjan and Klijn (2004) do not use the terms "processoriented" and "problem-oriented" rules, nor do they make this distinction between rules.

81 Linda Senden, Soft Law in European Community Law (Oxford: Hart Publishing, 2004)

82 Aline Reichow and Bärbel Dorbeck-Jung, "How can we characterize nano-specific soft regulation? Lessons from occupational health and safety governance", in Kornelia Konrad et al. (eds), Shaping Emerging Technologies: Governance, Innovation, Discourse (Berlin: AKA, 2013), pp. 83-102.

83 Pierre Bourdieu, "The Force of Law: Toward a Sociology of the Juridical Field", 38 The Hastings Law Journal (1987), pp. 805-853.

84 Roscoe Pound, "Law in Books and Law in Action", 44 American Law Review (1910), pp. 12-36. can be set by both public and private bodies. While state institutions often set soft regulation in form of communications or recommendations, non-state organisations, such as business associations, frequently set soft rules in form of codes of conduct or guidelines. Soft rules can have an autonomous steering role, but also adopt the roles of preparing the ground for hard regulation-i.e. regulation that is legally binding, with non-compliance being backed by sanctions through enforcement agencies and/or the courts-and contributing to the interpretation and implementation of hard regulation. ${ }^{82}$

Rather than perceiving soft and hard regulation as dichotomic, this article considers gradations between the two. As such, we can think of soft and hard regulation on a continuum on which soft rules can 'harden' through processes of formalisation. From a sociology of law perspective, formalisation can occur through the codification of soft rules in legal texts, as well as through their linguistic expression by public authorities. More specifically, sociology of law scholars emphasise that law is closely tied to social realms and practices; law does not merely encompass written texts but as much its application within social realms. ${ }^{83}$ Accordingly, we may speak of 'lawin-books' (i.e. texts of the law such as judicial decisions, commentaries or recommendations that formalise through codification) and 'law-in-action' (i.e. linguistic expressions by legal professionals in social reality that formalise through public authority). ${ }^{84}$ Taking a pragmatic approach to this conception in this article soft rules may become 'hardened' through formalisation: namely, through written reference in texts of the law and/or through oral reference by public authorities. For instance, a guideline developed by industry for the safe handling of nanomaterials in workplaces can become hardened through its recommendation for use in a policy brief by a federal OHS agency. In this way, rules become more durable and possibly binding.

While hardened rules provide certainty that those who follow the rules behave in the best possible way under specific circumstances, they also level down the playing field, i.e. regulated parties have less flexibility to decide how to behave under particular circumstances. Typically, soft rules can play an important role in risk and technology regulation due to their open and flexible character that allows responding quickly to the dynamics of knowledge development and facilitating adaptation to new insights in- 
to technological risks. ${ }^{85}$ Under such conditions institutional learning can emerge, which shapes the relations among actors in the network for the long term. As a result, institutional uncertainty in processes of cooperation is reduced because actors and the network become linked through explicit rules that facilitate interaction.

These relatively stable structures enable actors to identify each other and to know about the modus operandi of interaction with one another. In other words, actors gain certainty about behaviour under specific circumstances. ${ }^{86}$ When actors commit to formalised rules, a network structure becomes more resistant to conflicts among individual actors and the rules themselves become durable. ${ }^{87}$

Thus, the key characteristic of institutional learning is rules. Rules decrease uncertainty in the network because they provide guidance for actors under specific circumstances. The development of rules can be investigated by means of three conditions.

First, the "development of informal agreements" among network actors can provide the foundation, or pre-condition, for formalised rules in the future. ${ }^{88}$ Such informal agreements are based on unwritten agreements that may be tacit or implicit, meaning collaborators are not aware of them. Nevertheless, these informal agreements guide their behaviour because network actors have come to converge perceptions and viewpoints over time. ${ }^{89}$ Unwritten agreements can be both problem- and process-oriented.

Second, informal agreements can provide the foundation for the "design of soft rules of behaviour". Over time informal agreements among collaborators may be put in writing and can develop into soft rules of behaviour, which tell actors what ought to be done under certain circumstances. As such, soft rules provide guidance by suggesting appropriate activities and structures for actor behaviour. ${ }^{90}$ Soft rules-either processor problem-oriented-may take the form of codes of conduct, guidance material or industry standards.

Third, "soft rules can become hardened" through formalisation. Process-oriented soft rules may become formalised through their development into agreements like contracts or publicly available documents by public authorities. As such, uncertainty as to the proper modus operandi among actors in collaborative processes is reduced. Thereby the collaborative network structures are stabilised. In contrast, problem-oriented soft rules may become hardened through codification of these rules in legal texts, as well as through their linguistic expression by public bodies with high authority in the political landscape. The hardening aspect implies that rules can become more durable over time thereby setting a certain regulatory standard. In effect, uncertainty as to the proper modus operandi of regulatees-in this case companies that manufacture nanomaterials-in applying risk assessment to nanomaterials is reduced. Actors have learned how to apply (specific parts of) risk assessment to nanomaterials. As such, an essential precondition for compliance with OSH legislation is fulfilled (i.e. the legal duty to provide safe workplaces through conducting risk assessment for (potentially) hazardous chemicals).

\section{b. Application to the Case of Nanomaterials}

In the VCI collaborative activities, all conditions of institutional learning were met, i.e. strong learning emerged. Various process- and problem-oriented agreements were made during the collaborative activities. Importantly, various problem-based agreements were developed further into soft rules to support efforts to make risk assessment applicable to certain nanomaterials. Some of these rules became hardened. For example, based on joint workshops initiated by the VCI and the Federal Institute for Occupational Safety and Health (BAuA) $(2005,2007)$, informal agreements were made to conduct a survey on nanomaterials health and safety practices among VCI member companies. The survey results were to be used to develop the Guidance for Handling and Use of Nanomaterials at the Workplace (2007) (which was updated in 2011). The rules underlying the guidance became hardened, i.e. formalised, through their linguistic expression by public authorities and

85 Diana M. Bowman and Graeme A. Hodge, "Counting on codes: An examination of transnational codes as a regulatory governance mechanism for nanotechnologies", 3 Regulation \& Governance (2009), pp. 145-164.

86 Koppenjan and Klijn, Managing Uncertainties, supra, note 24.

87 Christopher Hood and Michael Jackson, Administrative Argument (Dartmouth: Aldershot, 1991).

88 Maurits Barendrecht et al. Trendreport Rulejungling. When lawmaking goes private, international, and informal (The Hague: Hiil, 2012).

89 Erik-Hans Klijn, "Rules as Institutional Context for Decision Making in Networks: The Approach to Post-war Housing Districts in Two Cities", 33(3) Administration and Society (2001), pp. 133-164.

90 Scharpf, Games real actors play, supra, note 25 
through reference to them by a regulatory body in documents that present the state-of-the-art on nanomaterials: first, therefore, the rules were discussed extensively by policy representatives in the context of the NanoDialog where they served as a resource for the development of another soft regulation instrument. Second, the guidance was hardened through take up by the Hazardous Substances Committee (AGS). The AGS advises the Federal Ministry of Labour and Social Affairs (BMAS) and concretises the Hazardous Substances Ordinance. The AGS referred to the BAuA/VCI guidance in a report (2010) that reviewed the state-of-the-art of nanomaterials OSH. On this basis, in 2013, the AGS developed the Announcement on Hazardous Substances 527 with advisory character in order to describe the state of knowledge on nanomaterials OSH practices including risk assessment. The Announcement made reference to the BAuA/VCI guidance. Today, i.e. in 2016, the AGS is discussing possibilities for developing the Announcement into a Technical Rule for Hazardous Substances (TRGS). When an employer follows a TRGS with advisory character it is assumed that this employer complies with OSH legislation. The employer may decide to apply another measure but must prove through the documentation of risk assessment that this measure is equally effective. Considering this process, the AGS has contributed to the hardening of the soft instrument.

In this section an analytical framework was developed, and applied, that enables evaluating collaborative activities as learning process towards effective nanomaterials OSH regulation. In the VCI collaborative activities the majority of the conditions for each learning type were met. Hence these activities contributed strongly to effective nanomaterials OSH regulation in Germany. A broad set of public and private actor groups engaged in the debate to uncover the potential human health risks of nanomaterials. These diverse actor groups succeeded to develop relationships characterised by trust. On this basis, state-ofthe-art rules were developed and hardened that enable companies to handle nanomaterials in workplaces (more) safely.

\section{Conclusions and Discussion}

The argument brought forward in this article is that learning is crucial to the process of effective technol- ogy regulation under conditions of scientific uncertainty. A process-oriented perspective was proposed for the effective regulation of nanomaterials in the OSH environment. Due to the uncertainty surrounding the potential health risks of certain nanomaterials, it is challenging for employers to comply with their legal obligation to conduct risk assessment for nanomaterials. In order to become rule-compliant, the regulated parties need to learn continuously how to apply general OSH obligations to the specificities of certain nanomaterials. New knowledge, generated through collaborative activities, is useful for regulators to ensure science-based OSH rules aimed at protecting workers. When regulators collaborate with the regulated parties in governance networks that create win-win situations for the involved actors, mutual learning can emerge.

For the analysis how collaborative activities in governance networks contribute to effective nanomaterials OSH regulation, an analytical framework was proposed. Contribution to effective regulation is determined by three types of learning: substantive learning (scientific expertise), strategic learning (trust), and institutional learning (rules). For each learning type, conditions were identified under which learning emerges.

The application of the analytical framework to the case study of nanomaterials OSH in the German context has tentatively indicated the usefulness of the framework. The analysis highlighted the vast development of Germany's governance landscape related to nanomaterials in the last decade. From an initial state of abstract uncertainty regarding the potential health risks of nanomaterials and how to manage these risks, we have now entered a more pronounced debate. A growing knowledge base has paved the way for the development of new approaches to the assessment and management of the risks of specific nanomaterials. Diverse actor groups including regulators, industry, and (federal) research institutes are participating in this debate. Thereby a complex governance landscape is created in which there is a need to satisfy individual and common interests and strategies so as to ensure an ongoing learning process regarding the health risks of nanomaterials and to be able to translate these findings into regulation.

Given this complex "game" of collaboration, it may be useful in the near future to have some sort of steering in place to facilitate strategically sound network collaboration. Network management is a 
form of steering on the meta-level to promote cooperative strategies, which may be aimed at facilitating interaction among actors ${ }^{91}$ or at creating or changing structures to facilitate improved coordination. $^{92}$ A network manager can be perceived as an entity that functions as point of intersection within a collaborative network and that takes up responsibility naturally over time in the process of cooperation. Network management can also be useful for building and improving trust relationships among actors. ${ }^{93}$

As mentioned earlier, trust among network actors seems to be crucial for collaborative processes. However, it may be necessary to caution against the development of "too much" trust, i.e. "blind trust", among collaborators. This is the more relevant when regulators cooperate with industry. Representatives of industry can "capture" regulators through ongoing relationships and regular repetition of encounters with the same individuals. While no instances of capture were observed in the case study, this certainly does not imply that capture did not in fact exist. Rather, it would seem likely that capture was forestalled through applying a form of tripartism, i.e. by having the independent non-profit Society for Chemical Engineering and Biotechnology steer and organise discussions in an impartial manner.

To avoid capture, it may be "healthy" to have some degree of distrust among actors in a network. Suspicion, a component of distrust, can generate a sharpened sense of vigilance towards collaborators, thereby creating awareness among all network actors of the need to prevent actions that are not in the public interest. In this respect, it is important to better understand how distrust and trust can co-exist among collaborators without this leading to the termination of collaborative ties.

Research into how trust and distrust can co-exist is also relevant in light of the relations between the three learning types and the central role that trust plays in them. Strategic learning appears to be a pre- condition, and amplifier, of substantive learning. When relationships among collaborators are characterised by trust, collaborators are more likely to exchange relevant knowledge and information because they are prepared to take risks and are more open towards each other. This, in turn, can enhance problem-solving capacity and the potential for finding innovative solutions to regulatory challenges based on newly generated knowledge. It can also be assumed that strategic and substantive learning are pre-conditions for institutional learning. When collaborators trust each other and have succeeded in generating new knowledge, this can pave the way for the development of agreements and rules. This is likely as the collaborators have the necessary knowledge available and they probably believe that these rules will not be detrimental to them.

There is a need for empirical investigation of the assumed importance of trust in collaborative activities. The proposed conditions for the trust development process are merely initial. Further specification and validation are needed. Accordingly, it may be useful to structure investigations by distinguishing between specific "stages" in trust development, for example a pre-trust phase (antecedents of trust), a trustbuilding and trust-maintenance phase, and a truststrengthening/weakening phase (consequences of trust). Research of this kind may help to improve our understanding of what constitutes the successfulness of public-private networks. Overall, there is a need for closer exploration of the limits and opportunities that a governance network perspective can bring to the field of regulation.

91 John K. Friend, John M. Power and Chris J.L. Yewlett, Public Planning: The Inter-corporate Dimension (London: Tavistock, 1974).

92 Scharpf, Interorganizational policy, supra, note 27

93 Michael McGuire, "Collaborative Public Management: Assessing What We Know and How We Know It", 66 Public Administration Review (2006), pp. 33-43. 